\title{
The Status Quo of Musical Instrument Education in China_-Taking Saxophone as an Example
}

\begin{abstract}
Yu Xin
Shanghai Conservatory of Music, Shanghai, China

Keywords: saxophone; musical instrument education; development status

Abstract: China's saxophone education is relatively backward, which is still in the primary stage at present. Compared with foreign countries, the gap is relatively large. To improve this situation, China's saxophone education is investigated. Through literature analysis and investigation analysis, the current teaching of saxophone in China is deeply analyzed. The results show that the problem of saxophone teaching in China is manifested in the fact that teachers' teaching methods are inappropriate and students' saxophone performance is weak. The problems of students are shown in improper breath control when students play saxophones; inaccuracy of basic lip-type; inadequate training of timbre; lack of rhythm in students' performance; the training of basic fingering needs to be strengthened. Countermeasures and suggestions are proposed for saxophone education in China from the following aspects: improve teachers' professional level and strengthen students' basic liptype and timbre training; combine the use of breath with scientific fingering to make music performance more perfect; use a variety of teaching methods to strengthen the assessment and focus on cultivating students' musical appreciation ability, pay attention to the aesthetic education function of saxophone performance. Therefore, it is necessary to improve the current situation of saxophone education in terms of teachers' teaching and students' learning.
\end{abstract}

\section{Introduction}

The saxophone is a musical instrument with a history of more than 140 years. Its tone is not only strong and energetic like a brass-wind instrument, but also graceful and pure like a woodwind instrument. During its introduction into China for nearly a century, saxophone has been popular with its changeful music style and unique tone. It was once praised as "an unparalleled musical instrument”. Today, saxophone is becoming more and more popular in China, and many students and even adults are joining the team to learn saxophones. The prosperity of saxophone art in China is very gratifying. However, as the field of saxophone education and performance in China is still in its infancy, it is far from the international level. The saxophone that is heard in audiovisual products is different from the saxophone that is now taught in professional schools. Many learners of saxophones and even teachers are not sure how the saxophone should be positioned. Even some students now use the saxophone to blow out sounds like clarinet. In fact, saxophone is also a timehonored instrument with a very systematic education method and playing method. In our country, the reason why the saxophone is welcomed and loved by people is because of the "Going Home" 
played by Kenny G many years ago. This piece of music makes more people know a new instrument, heard his tone and its rich musical expression. With the rapid development of popular music and jazz music in China, saxophone has become a popular musical instrument. More and more people like it, but the education problem of saxophone also follows.

\section{Literature review}

Cui (2016) believed that saxophone is favored by more and more people with its fashionable appearance, unique tone and strong appeal. How to improve the cultivation of timbre and improve the performance of saxophone has become an important research topic. Emphasis will be placed on the nature of saxophones, the factors that affect its timbre, and the methods to cultivate timbre for in-depth study [1].

Feng (2015) believed that more and more saxophone compositions have the characteristics of "crossover". Crossover is a term to describe the classic environment of the fusion of popular music styles. There is also evidence that college music education is a more diversified curriculum that emphasizes ethnomusicology. Due to the trend of composition and education, the training of classical and jazz disciplines by phonetics is becoming more and more important. The problem is that although many universities have set saxophone majors, there is a huge difference between classical and jazz education. This makes it impossible for students to perform cross music accurately with the saxophone music level of performance, despite receiving the bachelor's degree, or to have the opportunity to perform jazz and other types of music. The purpose of this study is to create a new saxophonist's degree track to promote diversity in performance [2].

$\mathrm{Li}$ (2016) took college students as research objects. According to the investigation, there were two main reasons for university students to study saxophone: one is professional study, the other is elective course. For the second kind of students, their common habit was that they will study hard at the beginning, but gradually lose interest in learning, and eventually just study for credits or even drop out. Based on years of teaching experience, the key to teach the second group of learners is to adopt targeted teaching methods to maintain students' interest in learning. College teachers should not only teach learners the performance skills, but also guide them to develop their interest in learning, laying a solid foundation for them to enter the society, because college students are at a turning point in their lives. In this respect, the significance of cultivating students' interest in saxophone learning is expounded, the reasons affecting students' interest in learning are analyzed, and the ways to effectively cultivate students' interest in learning are discussed, that is, when choosing the course, it is necessary to grasp the learning psychology of college students, adopt a targeted teaching method, provide appropriate music, and establish a good stage performance style [3].

$\mathrm{Li}$ (2016) believes that learning is endless and knowledge is endless. While strengthening their own learning, people must actively expand their horizons. On the one hand, people should actively learn the professional theories of saxophone and enrich their artistic theory. On the other hand, people also need to strengthen their study, actively create conditions to participate in more highlevel performance activities, and learn more practical and advanced practical experience, so as to improve their comprehensive artistic quality and lay a solid foundation for higher level performance skills [4].

Wei (2016) proposed to control breath reasonably. The sound of the saxophone is generated by the exhalation of the human body to make the whistle piece vibrate, so the player's breath is the basis for the performance. The breath of the performer directly determines the performance of the saxophone [5].

$\mathrm{Su}$ (2016) suggested that the quality of the saxophone is the foundation. This requires a 
comprehensive consideration in choosing a saxophone. For example, the quality of the instrument itself, the selection of the overall material, the material quality of the accessories such as the whistle piece and the mouthpiece, and the workmanship techniques all play an important role in the performance of the saxophone. If these aspects are inferior, even if the performer's skill level is superior, it is impossible to play a high level of effect. In general, it is necessary to purchase highquality saxophone instruments to lay a material foundation for high-quality performance [6].

\section{Methodology}

\subsection{Document analysis method}

Through the study of the collected literature data in a certain aspect, the nature and status of the research object are explored, and the analysis method is introduced. By referring to the domestic and foreign literature on saxophone teaching and combining the current situation of saxophone education in China, the existing problems and development situation of musical instrument education in China are discussed.

\subsection{The method of investigation and analysis}

Objective: to understand the teaching status and provide reliable data support through issuing questionnaires to several different levels of higher education institutions. The main contents include the teaching organization of the saxophone in higher education institutions, the situation of teachers, the content of teaching and the willingness of students to learn.

Respondents: questionnaires are conducted in 12 universities in Hunan province, Hubei province, Fujian province, Chongqing province, Guizhou province, Sichuan province, Yunnan province, and Jiangxi province. The universities surveyed include deployed, provincial and local colleges. The subjects of the survey are saxophone learners in grades 1-4 of music education majors in higher normal colleges or professional colleges.

Survey tool: the questionnaire prepared with saxophone teaching in normal university as the main content.

Distribution of questionnaires: a total of 70 questionnaires are issued and 61 are returned. The recovery rate is $87 \%$, and the adoption rate of the returned questionnaire is $100 \%$.

The analysis of survey results is shown in table 1:

Table 1Questionnaire results

\begin{tabular}{|c|c|c|c|c|}
\hline Options & $\begin{array}{c}\text { A The need for } \\
\text { college entrance } \\
\text { examination }\end{array}$ & $\begin{array}{c}\text { B Love } \\
\text { saxophone very } \\
\text { much }\end{array}$ & $\begin{array}{c}\text { C Hope to have a } \\
\text { professional skill }\end{array}$ & Others \\
\hline $\begin{array}{c}\text { Number of } \\
\text { people }\end{array}$ & 3 & 51 & 4 & 3 \\
\hline
\end{tabular}

According to the table of the survey, students' main motivation for learning saxophone comes from their hobbies, which indicates that most students learn the instrument with a positive attitude. Therefore, in the teaching process, it is necessary to vigorously explore the interest and enthusiasm of the students. 


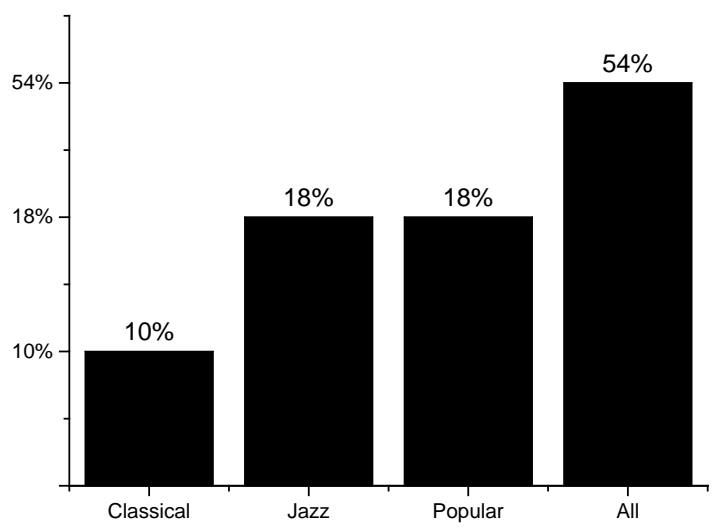

Figure 1 Student learning willingness survey

Through the survey of students' willingness to learn, it is found that only $10 \%$ of students hope that the teaching content is mainly classical. The number of students who hope that the teaching content is mainly jazz and popular is the same, accounting for $18 \%$ of the students, while those who hope that the teaching content is all three styles accounted for 54\%. It indicates that the teaching content should be rich, and the diversified courses should cover a wide range to meet the needs of students, as shown in figure 1.

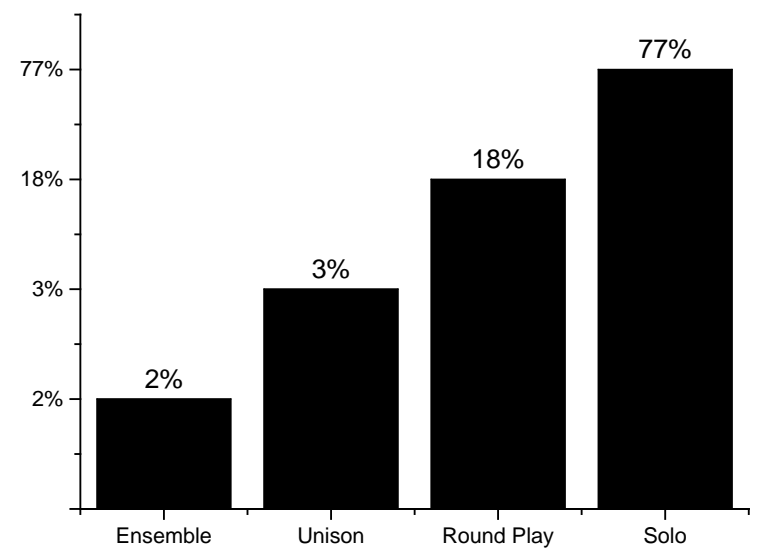

Figure 2 Teaching group

It can be concluded from figure 2 that the teaching organization tends to group lessons, but it fails to give play to the advantages of the organizational form. Through investigation and analysis, more and more instrumental music teaching organizations in colleges and universities have gradually changed from individual teaching to group teaching. The implementation of group courses is to save education resources and improve teaching efficiency, but this advantage is not fully displayed in the actual teaching process, and at the same time, it also cuts students' class time to some extent. 


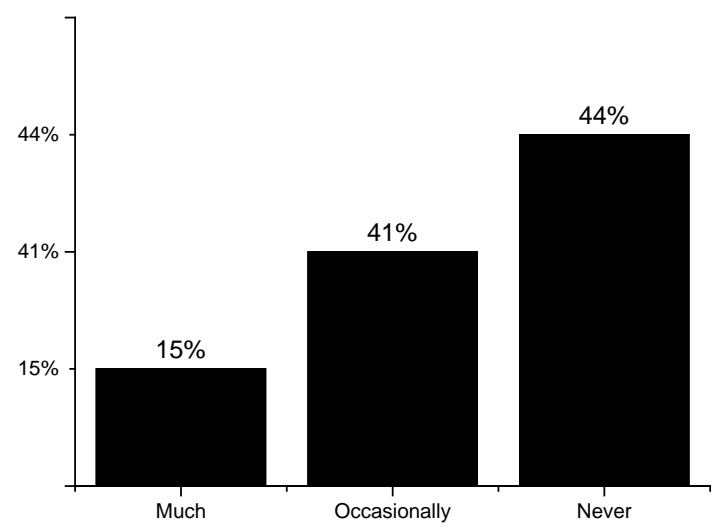

Figure 3 Teaching equipment usage

The survey found that more than $80 \%$ of students have little or no access to multimedia equipment, and less than $20 \%$ of students have been taught by multimedia in class, as shown in figure 3.

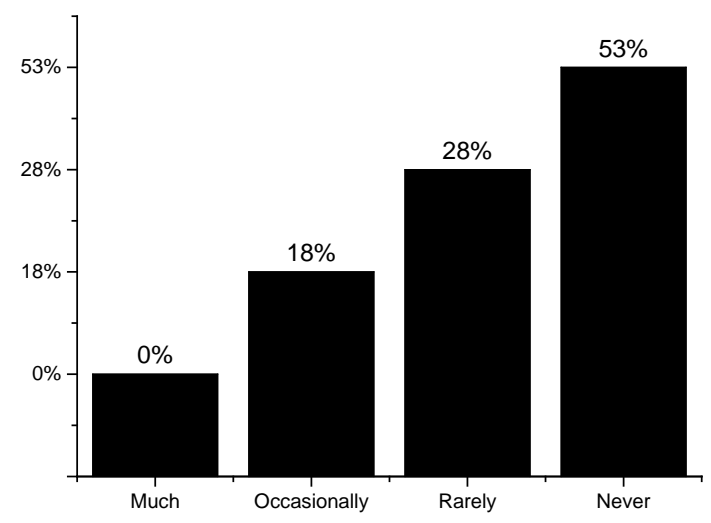

Figure 4 Teaching practice

In figure 4, from the results of the survey feedback, the situation is not optimistic. The number of students who choose to get a lot of saxophone teaching practice opportunities is zero, with only $18 \%$ of those who choose occasionally, $28 \%$ of those who choose rarely, and $54 \%$ of students who have never had the saxophone teaching practice opportunities.

\section{Results}

\subsection{Analysis of current situation of saxophone teaching in China}

Since the reform and opening up, the saxophone's performance and teaching have been very popular. Some colleges and universities in China offer saxophone teaching courses, which are of great significance in improving students' saxophone performance and enhancing their saxophone performance skills. Although the teaching of saxophone has achieved certain results, some problems in basic teaching have been found after the analysis of relevant questionnaires for students in some colleges and universities. 
Teachers play a dominant role in teaching activities. Whether teachers' teaching methods are appropriate is the key to determine whether the saxophone teaching is effective. At present, one of the problems in saxophone teaching is that the teachers' teaching methods are not correct. Some teachers only pay attention to the theoretical teaching of saxophone and ignore the cultivation of students' practical playing ability. There are also teachers who lack patience and professionalism in teaching and have poor attitude towards students. Some teachers are eager for success, and they criticize students who are slow in learning, which will demotivate students' learning enthusiasm and have a negative influence on the teaching effect of saxophone to some extent.

\subsection{Students’ problems in learning saxophone}

Students can't control breath when playing saxophone. The use of breath is the basic skill for playing saxophone and an important means to display the timbre of saxophone effectively. Some saxophone teachers don't pay attention to training the use of breath, so that students control the breath improperly. Many beginners don't exhale or inhale properly, when playing saxophone, their breath is not uniform scattered and intermittent, the alternated breathing is not timely. Improper breath control can only reduce the performance of saxophone, which has a negative impact on the improvement of saxophone performance.

The basic shape of a mouth when a person is speaking or pronouncing a certain sound is not accurate, timbre training is not in place. One of the problems in saxophone teaching is that teachers don't have strict requirements on students' basic mouth shape. The mouth shape is a factor that directly affects the intonation of the saxophone. When playing the saxophone with the right mouth shape, it makes a beautiful, loud, and touching sound. In the teaching of saxophone, students have a wide variety of mouth shapes and the timbres are uneven. Insufficient demonstration of teachers, insufficient attention to the correction of students' wrong mouth shape, and lack of patience, which makes students' progress in learning very slow.

Students' performance lacks sense of rhythm and basic fingering training needs to be strengthened. Teachers don't pay enough attention to the education of students' musical knowledge and music appreciation ability, and students don't grasp the melody. When playing saxophone, the students lack a sense of rhythm and can't play the tune according to the music score. In addition, the teacher lacks patient guidance for the basic fingering of students when playing the saxophone, which makes many students unable to use fingering correctly and directly destroys the integrity of music rhythm. Some students' fingers are not relaxed enough, their fingers are raised too high, and the buttons are pressed too hard. These wrong fingering methods directly affect the timbre and intonation of the saxophone, and further affect the performance level.

\section{Discussion}

\subsection{Improve the professional level of teachers and strengthen the basic shape of a mouth and timbre training of students}

The shape of a mouth when a person is speaking or pronouncing is the basic skill for playing saxophone. Correct mouth shape can play beautiful timbre. Saxophone teachers should pay attention to the basic shape of a mouth requirements when guiding students. When playing the saxophone correctly, the mouth is slightly open, and one third of the slope of the mouthpiece is placed in the middle of the mouth, the lower lip is slightly raised, and the upper teeth gently bite the mouthpiece. The teacher should patiently teach every detail, make the demonstration performance, and ask the student to practice repeatedly. The instrument itself has treble section and bass section. The teacher should teach the students to play different tones with different strength. Through 
teacher's demonstration, students gradually strengthen the perception of saxophone and establish the concept of timbre, which is very beneficial to playing saxophone.

\subsection{Combine the breath application with scientific fingering}

Teachers should strengthen the breath training of students when playing saxophone. Breath control is one of the basic aspects of saxophone performance. The teacher should train the students to breathe in and breathe out, and make sure that the students' breath is even when playing the saxophone. Strength should vary according to the rhythm, the effective control of breath is the method to guarantee the intonation. In addition, correct fingering is the key to playing saxophone. The position and height of the fingers, as well as the falling force, are the assistant gestures when playing saxophone, which are the factors to improve the overall level of saxophone performance.

\subsection{Use a variety of teaching means to strengthen assessment}

Some saxophone teachers of the art majors always follow the traditional teaching mode. This teaching method is old-fashioned. Now, in the era of knowledge and information, education should also present novel and efficient features. Saxophonist teachers should learn to use multimedia teaching system for teaching, play music or saxophone performance videos in class, let students experience the beauty of saxophone performance. Teachers can also divide students into groups to discuss the same saxophone music, including performance styles, basic techniques, strengths and weaknesses of this style, and students can speak freely and participate effectively in classroom activities. This teaching mode is conducive to improving students' enthusiasm in learning saxophone.

\subsection{Pay attention to the music appreciation ability of students and the aesthetic education function of saxophone performance}

Any art discipline has a certain aesthetic education functions, and saxophone teaching is no exception. Through the teaching of saxophone, students can improve their attainment, temperament, cultural accomplishment and music appreciation ability, and have a deeper understanding of the thoughts and emotions expressed by saxophone. Teachers should start from cultivating students' aesthetic awareness and improving students' music appreciation ability, strengthen the emotional input of saxophone performance, so as to improve students' comprehensive level of saxophone performance.

\section{Conclusion}

In addition to material, people's pursuit of spiritual life also gradually improved, and instrumental performance is increasingly favored by people. Saxophone is a representative of western instruments, and saxophone courses have been carried out in universities in recent years. Although there are still some problems in the teaching of saxophone, the students' saxophone performance is constantly improving through effective measures and innovations in the teaching model. The discussion and analysis of the status quo of the development of saxophone teaching in China has played a vital role in the development of China's future musical instrument education and the improvement of students' artistic appreciation.

\section{References}

[1] Cui Yang. On the Factors Affecting the Saxophone Voice [J]. Culture and Education Materials, 2016(25):65-66. 
[2] Feng Zihao. On the Breath and Skills in Saxophone Performance [J]. Northern Music, 2015, 35(18): 59-60.

[3] Li Jianyi. A Brief Analysis of the Basic Skills of Saxophone Performance [J]. Shenzhou Folk Customs, 2016(3): 4346.

[4] Li Yunxiang. Thoughts on the Problems and Teaching Strategies in Saxophone Teaching Performance [J]. Public Art, 2016(8):223-223.

[5] Wei Yanan. Analysis of the Application of Breath in Saxophone Performance [J]. Education, 2016(7):00283-00283. [6] Su, Y. H., \& Salazar-López, E. (2016). Visual timing of structured dance movements resembles auditory rhythm perception. Neural Plasticity, 2016, (2016-5-30), 2016, 1-17. 